\title{
Effect of Bile and Fat on Gastric Motility under the Influence of Various Stimulants
}

\author{
J. J. Anderson, M.D., R. J. Bolt, M.D." B. M. Ulema., M.P.H., \\ and P. BAss, Ph.D.
}

\begin{abstract}
4 XPERIMENTAL studies in rats, dogs, and humans have demonstrated the 4 inhibitory effects of intraduodenal fat on spontaneous gastric motility. ${ }^{1-3}$ Most of these studies have been done with open-tip and balloon-pressure recordings. The experiments in animals are frequently done under acute conditions or with the gastrointestinal tract altered by fistulas. To overcome unreliability in the results obtained by these experimental methods, we recorded contractility of circular and longitudinal smooth muscle layers from the gastric body and antrum by using extraluminal force transducers. The size of the recording units and the implant procedure did not interfere with intraluminal contents and allowed chronic recordings without altering the physiologic environment. ${ }^{4-6}$
\end{abstract}

Since spontaneous gastric motility is intermittent, the inhibitory effect of fat was also tested against various stimulants. Fat inhibition of gastric motility is mediated through a humoral pathway. ${ }^{7}$ Frazer emphasized the importance of the physical state of fat for inhibition of gastric motility. Micellar fat is presumably the physical-chemical state under which lipids are most readily absorbed by the small bowel mucosa. ${ }^{9}$ For the above reasons, we used oleic acid, glycerol-1-monooleate, and bile under conditions conducive to micellar formation. ${ }^{10}$ While this study was in progress, Swan et al. reported that micellar fat, placed in a duodenal loop of dogs, exerted no inhibitory effect on the spontaneous motility of Heidenhain pouches. ${ }^{11}$

The purpose of this study was to determine, using extraluminal force transducers, (1) the effect on gastric contractility when saline, bile, or micellar fat was placed in a duodenal Thiry loop; (2) to see if the preparation in the duodenum differentially affected the gastric body or gastric antrum; (3) to determine if longitudinal or circular muscle layers were more susceptible to the inhibiting influence of substances placed in the duodenum; and $(t)$ to ascertain whether fat inhibition of motility was effective when stomach contractility was driven by various stimuli.

From the Cniversity of Michigan Medical Center and Parke, Davis and Company Research Laboratories, Ann Arbor, Mich.

- Present address: Division of Medical Sciences, University of California School of Medicine, Davis, Calif. 


\section{METHODS}

\section{Avimal Prepiritions}

The technic of constructing extraluminal force transclucers has been described. ${ }^{12}$ These were implanted into 6 healthy beagle dogs weighing approximately $10 \mathrm{~kg}$. and the following surgical procedure was performed (Fig. 1). The proximal duodenum was transected just below the common and

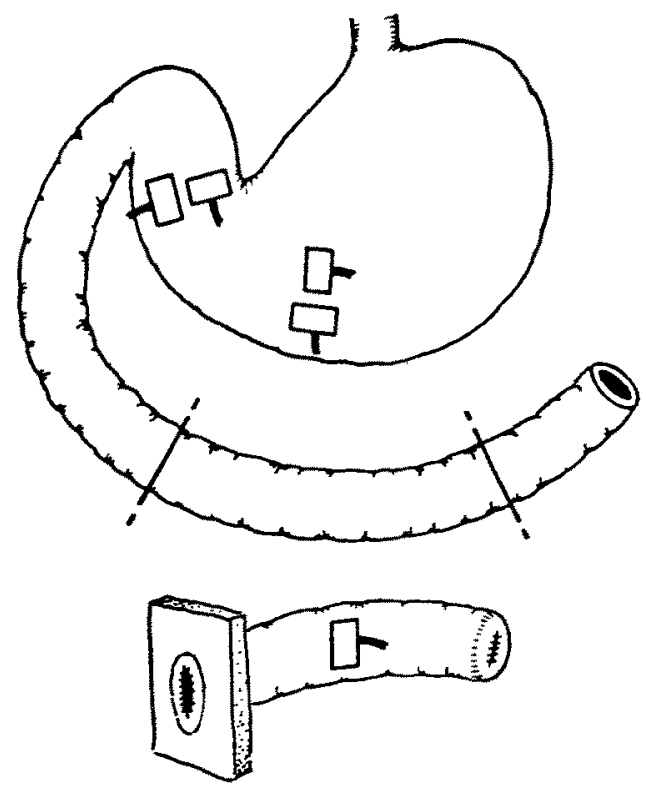

Fig. 1. Schematic representation of arrangement of extraluminal force transducers on bödy and antrum of stomach and on Thiry loop of duodenum. Transducers are arranged to record from either transverse or longitudinal axis of organ. Tracings taken from duodenal loop not included in this study.

pancreatic ducts. A 12-cm. Thiry loop was made with the stoma formed from the caudad end near the ligament of Treitz. The duodenum was anastomosed end to end.

\section{Experimental Procedure}

Gastric contractility was monitored for a $30-\mathrm{min}$. period while under the influence of stimuli and with "inhibiting" substances in the duodenal Thiry loop. The gastric stimuli used were: (1) food, $200 \mathrm{gm}$. of horse meat * (analysis: protein-11.5\%, fat-4.0\%, fiber-1.0\% intravenously at 2 concentrations: $50 \mu \mathrm{g} . / \mathrm{kg} . / \mathrm{min}$. and $200 \mu \mathrm{g} . / \mathrm{kg} . / \mathrm{min}$., and (3) 5-hydroxytryptophane (5 HTP) given intravenously at a concentration of $600 \mu \mathrm{g} . / \mathrm{kg} . / \mathrm{min}$. At the start of each experiment the stoma of the Thiry loop was sealed with a No. 16 Foley catheter and $10 \mathrm{ml}$. of one of the following substances was instilled after adjustment to $\mathrm{pH} 7$ : (1) $0.9^{\circ}{ }_{0}^{\circ} \mathrm{NaCl}$; (2) micellar fat, consisting of $2.5 \mathrm{m.M}$ of glycerol-1-monooleate and $5 \mathrm{~m} . \mathrm{I}$ of oleic acid in $100 \mathrm{ml}$. of dog bile diluted with $0.9_{\%}^{\sigma}$ sodium chloride in a ratio of $1: 10$; and

-Country Best Foods, Agway Inc., Syracuse, X. Y. 
(3) dog bile diluted with $0.9 \%$ sodium chloride in a ratio of $1: 10$. The substances were placed in the Thiry loop 1-3 min. before administering the gastric stimulants.

A total of six animals were prepared for this study. Each of 5 dogs was subjected to the following 18 randomired treatments. Four treatments replicated twice consisted of either instilling $0.9^{\prime \prime}$ sodium chloride into the Thiry loop and infusing Ach (50 or $200 \mu \mathrm{g} . / \mathrm{kg} . / \mathrm{min}$ ) or $5.11 T P(600 \mu \mathrm{g} . / \mathrm{kg} . / \mathrm{min}$.) intravenously for $30 \mathrm{~min}$., or feeding horse meat $(200 \mathrm{gm}$.). Two experiments consisted of placing saline in the loop and not administering gastric stimulants. The remaining 8 procedures consisted of challenging the gastric stimulants with bile in the loop in 4 experiments and micellar fat in the loop in 4 experiments. The sixth dog was used for establishing the dose response.levels of the stimulants and determining whether bile or micellar fat in the loop would antagonize spontaneous activity.

\section{Measurement and Analysis of Data}

The recorded tracings obtained from each muscle layer were analyzed for number and amplitude of contraction in a $30 \mathrm{~min}$. period. Contractions of $\mathbf{5} \mathbf{~ g m}$. force or greater were the only ones considered for measurement. Anything less was not easily differentiated from base line artifact. The amplitude was assessed using a "motility index" system. ${ }^{13}$ This was obtained by placing a calibrated (gram of force) transparent grid over the record and counting the number of contractions which fell within specific levels of force. Each contraction received a weighted score of $1,2,4,8$, or 16 , corresponding to recorded amplitudes of 5-10 gm., 10-20 gm., 20-40 gm., 40-80 gm., and > 80 gm., respectively. These scores were added together to provide an index for the 30-min. period. This approach considers the height of the deflection, the calibration of the sensors, the gain of the polygraph, and the entire period of observation.

The average height of contraction from each site monitored in a given 30 . min. period was also calculated by dividing the motility index by the number of contractions. This is referred to as the mean motility index. ${ }^{14}$ Analysis of variance was performed on these data, as well as on the number of contractions and on the motility index.

To assess the effectiveness of each of the inhibitors with each of the stimulants, a factorial design was utilized for the experiments. Since, however, certain cells had more replications than others, approximations in the analysis of variance were necessary to adjust for this. A measure of over-all effectiveness for the entire stomach was constructed by combining the corresponding measures for each of the 4 areas monitored. Further, to evaluate differences of muscle layers in both gastric body and antrum and between these 2 areas, the 3 corresponding paired differences also were subjected to a factorial analysis of variance. Significance was taken to be the .05 level. The 
terms "trend" or "tend to" are used when a numerical difference appeared which was not statistically significant.

\section{RESULTS}

Since the spontaneous contractile activity of the antrum and body is variable, the ability of bile or micellar fat to influence spontaneous conuactility could not be assessed. A single dog study confirmed the variability of the control pattern and the "false" impression that bile and micellar fat could inhibit gastric contractility (Fig. 2). An attempt to obtain a continuous motor pattern was made by administering stimulants.

General effects on the number of contractions in $30 \mathrm{~min}$. under the various conditions studied are seen in Table 1 . It should be emphasized that the expected number of contractions $(150 / 30 \mathrm{~min}$.) was not obtained since no contractions below $5 \mathrm{gm}$. of force were tabulated. The analysis of variance

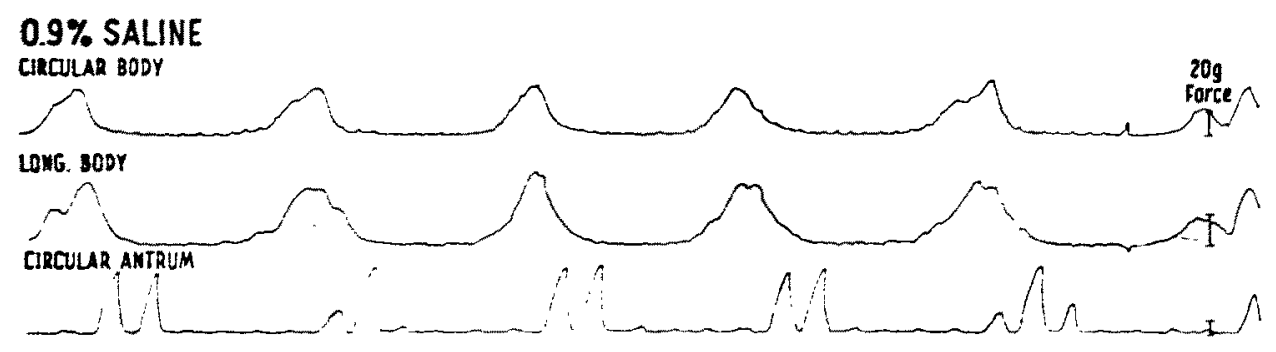

\section{BILE}

CIRCULAR soor

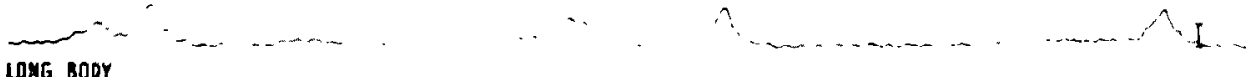

WNE. BODY

CIRCULAR ANTRLM

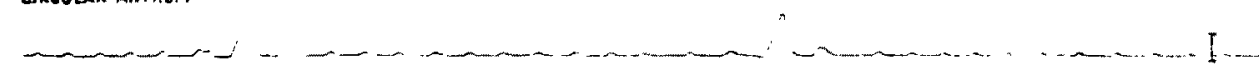

\section{MICELLAR FAT}

CIRCULAR BJOH

10NG. BODY

\section{CrRCULAR ANTRUM}

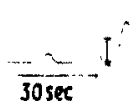

Fig. 2. Tracings of spontaneous response of 3 areas of stomach when saline, bile, or inicellar bet are instilled into Thiry loop of duodenum. Did latter two substances inhibit contractility or were these "normal" perioxls of quiescence? Tracings obtained from same animal on diferent days. Force bary correspond to $20 \mathrm{gm}$. of force. Time bar equals 30 -sec. duration. 
TABLE 1. MEAX NLUBER OF CONIRICTIONS IN WO MINLTES

\begin{tabular}{|c|c|c|c|c|c|c|c|}
\hline \multirow[b]{3}{*}{ Stimulant } & \multirow[b]{3}{*}{$\begin{array}{c}\text { Substance } \\
\text { in Thiry loop }\end{array}$} & \multicolumn{4}{|c|}{ No.contractions } & \multirow[b]{3}{*}{ Mean } & \multirow[b]{3}{*}{$\begin{array}{c}\text { Over-all } \\
\text { mean }\end{array}$} \\
\hline & & \multicolumn{2}{|c|}{ Castric body } & \multicolumn{2}{|c|}{ Gastric antrum } & & \\
\hline & & $\begin{array}{l}\text { Circ. } \\
\text { axis }\end{array}$ & $\underset{\text { axis }}{\text { Long }}$ & $\begin{array}{l}\text { Circ. } \\
\text { axis }\end{array}$ & $\begin{array}{l}\text { Long } \\
\text { axis }\end{array}$ & & \\
\hline Ach & Micellar fat & 32.8 & 6.6 & 14.8 & 16.6 & 17.7 & \multirow{3}{*}{20.0} \\
\hline \multirow{2}{*}{$(50 \mu \mathrm{g} . / \mathrm{kg} . / \mathrm{min})}$. & Bile & 23.4 & 2.4 & 19.8 & 30.4 & 19.0 & \\
\hline & Saline & 24.6 & 5.4 & 30.8 & 31.8 & 23.2 & \\
\hline Ich & Micellar fat & 20.6 & 8.2 & 62.0 & 68.1 & 39.8 & \multirow{3}{*}{37.6} \\
\hline \multirow{2}{*}{$(200 \mu \mathrm{g} \cdot / \mathrm{kg} \cdot / \mathrm{min})}$. & Bile & 25.4 & 6.6 & 52.2 & 52.2 & 34.1 & \\
\hline & Saline & 23.4 & 8.0 & 62.8 & 60.8 & 38.8 & \\
\hline \multirow{3}{*}{$\begin{array}{l}5 \text {-HTP } \\
(600 \mu g / \mathrm{kg} / \mathrm{min} .)\end{array}$} & Micellar fat & 107.0 & 27.8 & 92.2 & 92.4 & 79.8 & \multirow{3}{*}{99.8} \\
\hline & Bile & 127.8 & 69.0 & 131.0 & 134.0 & 115.1 & \\
\hline & Saline & 120.8 & $3^{4.4}$ & 117.2 & 1240 & 104.1 & \\
\hline Food & Micellar fat & 69.6 & 18.6 & 53.2 & 30.2 & 42.9 & \multirow{4}{*}{41.7} \\
\hline \multirow[t]{2}{*}{$(200 \mathrm{gm})}$. & Bile & 51.0 & 14.2 & 56.4 & 48.2 & 42.4 & \\
\hline & Saline & 62.0 & 15.6 & 45.0 & 36.4 & 39.8 & \\
\hline \multirow{2}{*}{\multicolumn{2}{|c|}{$\begin{array}{l}\text { Mean } \\
\text { Over-AlL MEAN }\end{array}$}} & 57.4 & 19.7 & 61.4 & 60.4 & & \\
\hline & & & & \multicolumn{2}{|c|}{60.9} & & \\
\hline
\end{tabular}

indicates that there was no statistically significant change in the number of contractions induced by the 3 stimuli-acetylcholine (2 doses), 5-HTP, and food-when either bile, micellar fat, or saline were in the loop. The number of contractions induced by 5-HTP in comparison with saline tended to be decreased with micellar fat (79.8 vs. 104.1 contractions) but not with bile (I15.4 vs. 104.1 contractions) in the loop (Table 1, Fig. 3). Under the influence of acetylcholine $(50 \mu \mathrm{g} . / \mathrm{kg} . / \mathrm{min}$.) the number of contractions in the antrum in both muscle layers tended to be decreased by micellar fat in the loop (Table $1,14.8$ vs. 30.8 and 16.6 vs. 31.8 ). Food is capable of producing a continuous motor pattern at all 4 sites monitored. This motor pattern was not altered by the various substances placed in the duodenal loop (Table 1 and Fig. 4).

In a paired comparison there were significantly more contractions in the circular muscle layer than in the longitudinal muscle layer of the body $\mathbf{( 5 7 . 4}$ vs. $19.7 ; \mathbf{F}=2.85$ ). In a paired comparison between the total number of contractions in the body vs. the antrum, there were significantly more contractions in the antrum (38.6 vs. $60.9 ; F=11.66)$. When combining the 4 sites monitored, the number of contractions under the various stimuli were significantly different from each other $(20.0,37.6,99.8$, and $41.7 ; \mathrm{F}=35.64)$ with 5-HTP being the most patent stimulant.

The data related to the number of contractions have also been expressed as per cent of activity (Fig. 5), taking 150 contractions as a maximal number of contractions in a $30 \mathrm{~min}$. period. This method of arranging the data indicates that even when stimulants are administered, it is dificult to obtain continuous activity against which to assess inhibitors of gastric motility. The 
standard errors of the means have been plotted as an indication of the variability among the $\overline{5}$ dogs when subjected to various experimental procedures. One may note the overlap of the standard errors by observation.

The amplitude of contractions under the various conditions are seen in Table 2. The values obtained are tabulated and expressed as "motility index." The analysis of variance indicates that neither bile nor micellar fat significantly decreased the amplitude of contractions induced by the stimuli. Though not statistically significant, the amplitude of contraction induced by 5-HTP or the lower dose of acetylcholine tended to be decreased by the micellar fat in the loop (Table 2 and Fig. 3). Food generates a continuous motor pattern of relatively low amplitude which could not be markedly reduced further with the substances placed in the loop (Table 2 and Fig. 4). Figure 4 demonstrates why $5 \mathrm{gm}$. of force was selected as the lowest measurable amplitude.

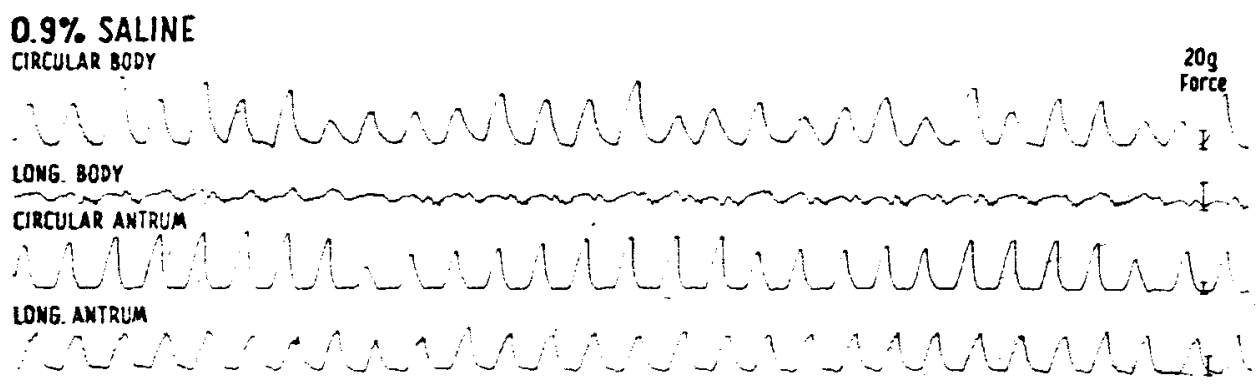

\section{BILE}

CIRCULAR BODY

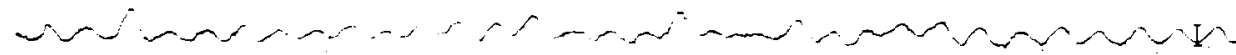

\section{LONG. BODY}

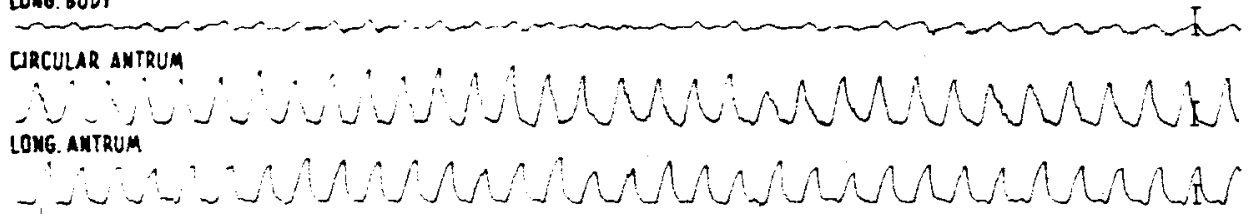

\section{MICELLAR FAT}

CIRCULAR BODY

CIn

LONG BODY

CIRCULAR ANTRUM

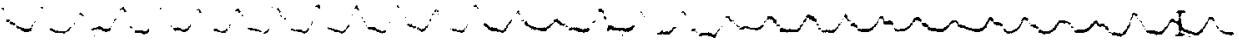
DONG ANTRIM

$30 \mathrm{sec}$

Fig. 3. Tracings of response of 4 areas of stomach when 5 -hydroxytryptophane (60) $\mu \mathrm{g} . /$ kg. min.) infused I.V. after saline, bile, or micellar fat were placed in duodenal Thiry loop. Tracings obtained from same animal on different dass. Trend of micellar fat to inhibit this type of activity not significaut. Calibration as in Fig. 2. 
Contractions lower than $5 \mathrm{gm}$. could not be clearly differentiated from baseline artifact.

In a paired comparison, the amplitude of the circular muscle layer of the body was significantly greater than that of the longitudinal muscle $(98$ vs.

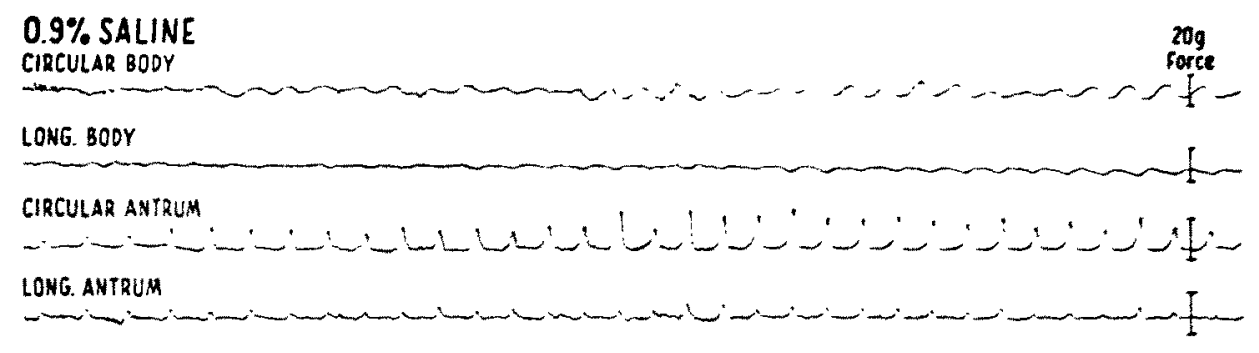

BILE
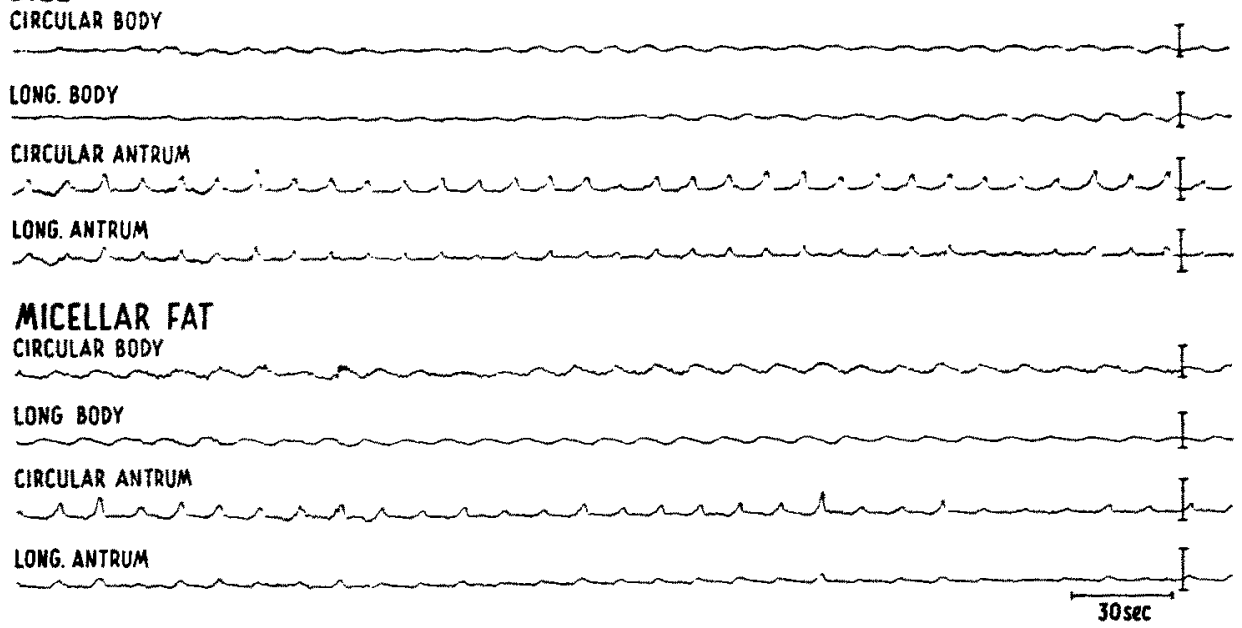

Fig. 4. Tracings of response of 4 areas of stomach following ingestion of horse meat (200 gm.) after saline, bile, or micellar fat were placed in duodenal Thiry loop. Tracings obtained from same animal on different days. Calibration as in Fig. 2.

25.2; $\mathrm{F}=24.92)$. A similar significant difference was found between the two muscle layers of the antrum (205.6 vs. $185.4 ; \mathrm{F}=4.63$ ). Comparing the total amplitude of contractions of the body vs. the antrum, the latter was significantly greater (61.6 vs. $195.5 ; \mathrm{F}=20.30$ ). Like the frequency results, the amplitude of contractions vary significantly under the influence of the different stimuli. For the over-all effect, we obtained a motility index of 38.7 , 108.0, 311.7, and 55.9, yielding $F=30.97$ with 5-HTP again being the most effective stimulant for contraction.

\section{DISCUSSION}

In a normal physiologic environment one can obtain many hours of recording from multiple leads. To quantify these records it is necessary to use 
some form of conversion from an analog signal to a digital form. Once in a digital format the data lend themselves to statistical analysis rather than to a simple description of the recorded motor patterns. Since multiple recordings are obtained from adjacent sites, a paired comparison among the various sites
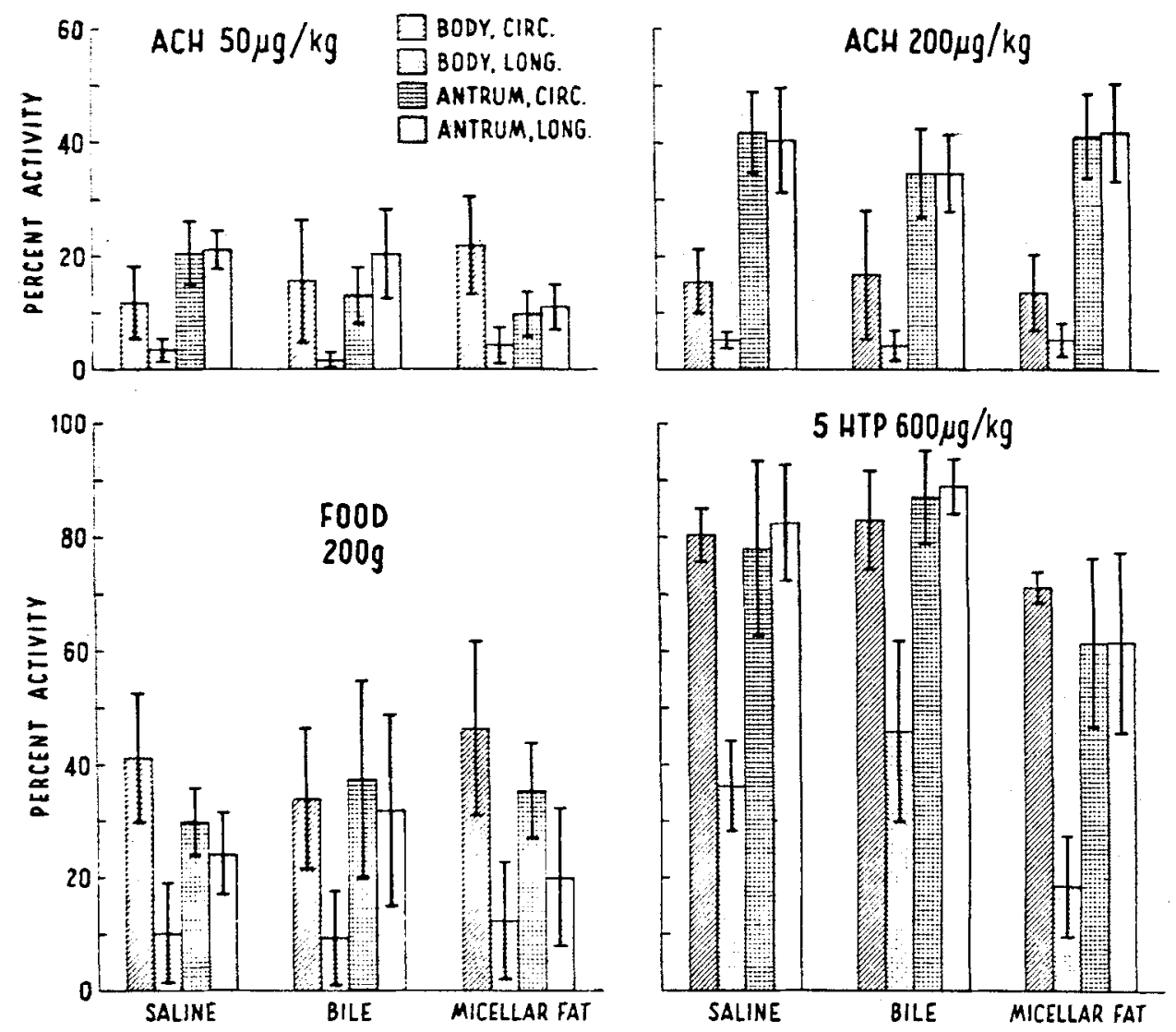

Fig. 5. Percentage of activity from areas of stomach in response to I.V. administration of acetylcholine ( 50 or $20 \% \mu \mathrm{g} . \mathrm{kg} . / \mathrm{min}$.), 5 -hydroxytryptophane $(600 \mu \mathrm{g} . / \mathrm{kg} . / \mathrm{min}$.$) , or$ ingestion of food $(200 \mathrm{gm}$.) after saline, bile, or micellar fat were instilled into duodenal Thiry loop. Bars represent standard errors of mean.

can be utilized in an analysis of variance. The contractions are relatively easy to enumerate. They may be quantified by expressing activity as the number of contractions in a given time period, or expressed as a percentage of activity of the expected number of contractions. The theoretic maximal frequency is readily available since the rate of gastric contraction for the sime preparition is remarkably stable. For example, it was possible to obtain 150 contractions in a 30-min. period. 12

The amplitude of contraction is an indication of the amount of work per. 
TABLE 2. AMPLITLDE OF CONIRICTION, IX G MIY. EXPRESED IS MOTILITY INDEX

\begin{tabular}{|c|c|c|c|c|c|c|c|}
\hline \multirow[b]{3}{*}{ Stimulant } & \multirow[b]{3}{*}{$\begin{array}{c}\text { Substance } \\
\text { in Thiry loop }\end{array}$} & \multicolumn{4}{|c|}{ No. contractions } & \multirow[b]{3}{*}{ Hean } & \multirow[b]{3}{*}{$\begin{array}{c}\text { Over-all } \\
\text { mean }\end{array}$} \\
\hline & & \multicolumn{2}{|c|}{ Castric body } & \multicolumn{2}{|c|}{ Gastric antrum } & & \\
\hline & & $\begin{array}{l}\text { Circ. } \\
\text { axis }\end{array}$ & $\begin{array}{c}\text { Long } \\
\text { axis }\end{array}$ & $\begin{array}{l}\text { Cite. } \\
\text { axis }\end{array}$ & $\begin{array}{l}\text { Long } \\
\text { axis }\end{array}$ & & \\
\hline Ach & Micellar fat & 39.8 & 7.2 & 24.2 & $2 \pi .0$ & 24.6 & \\
\hline$(50 \mu \mathrm{g} . / \mathrm{kg} . / \mathrm{min})$. & Bile & 27.0 & 2.4 & $\begin{array}{r}44.4 \\
1128\end{array}$ & 57.4 & 32.8 & 38.7 \\
\hline Ach & Micellar fat & 30.2 & 9.2 & 224.8 & $\begin{array}{r}69.6 \\
163.8\end{array}$ & 107.0 & \\
\hline$(200 \mu \mathrm{g} . / \mathrm{kg} . / \mathrm{min})$. & $\begin{array}{l}\text { Bile } \\
\text { Saline }\end{array}$ & $\begin{array}{l}34.4 \\
45.6\end{array}$ & $\begin{array}{l}9.6 \\
8.4\end{array}$ & $\begin{array}{l}217.2 \\
285.2\end{array}$ & $\begin{array}{r}99.6 \\
168.0\end{array}$ & $\begin{array}{r}90.2 \\
126.8\end{array}$ & 108.0 \\
\hline 5-HTP & Micellar fat & 187.4 & 32.0 & 361.6 & 301.2 & 220.6 & \\
\hline$(600 \mu \mathrm{g} \cdot / \mathrm{kg} \cdot / \mathrm{min})$. & $\begin{array}{l}\text { Bile } \\
\text { Saline }\end{array}$ & $\begin{array}{l}278.0 \\
297.2\end{array}$ & $\begin{array}{l}97.6 \\
79.2\end{array}$ & $\begin{array}{l}539.2 \\
447.2\end{array}$ & $\begin{array}{l}598.0 \\
521.6\end{array}$ & $\begin{array}{l}378.2 \\
336.3\end{array}$ & 311.7 \\
\hline Food & Micellar fat & 73.4 & 19.2 & 66.8 & 63.6 & 35.8 & \\
\hline$(200 \mathrm{gm})$ & $\begin{array}{l}\text { Bile } \\
\text { Saline }\end{array}$ & $\begin{array}{l}52.6 \\
64.6 \\
98.0\end{array}$ & $\begin{array}{l}14.2 \\
17.2 \\
25.2\end{array}$ & $\begin{array}{r}91.0 \\
52.6 \\
205.6\end{array}$ & $\begin{array}{r}102.2 \\
52.5 \\
18.5 .4\end{array}$ & $\begin{array}{l}65.0 \\
16.8\end{array}$ & 55.9 \\
\hline OVER-ALL MEAN & & & & & & & \\
\hline
\end{tabular}

formed by the muscle and can be obtained by measuring the height of the contraction. The assessment of these data can be a tedious task and we have limited it to selected sampling periods. The problems of assessing motility tracings have been expressed by others. ${ }^{1 ;-17}$

To take into account both the amplitude and the frequency of contractions, we utilized the motility index approach of Jacoby and Brodie. ${ }^{13}$ The principle of this method is to enumerate contractions of similar amplitudes and assign weighted scores.

Using these methods, we could not demonstrate a statistically significant motor inhibition of the stomach when fat was present in the duodenum. This is not in accord with data obtained by Farrell and Ivy ${ }^{7}$ and Quigley, Zettelman, and $I^{1} y^{1}$ in the dog or by Menguy in the rat. Our results are more in agreement with studies on humans performed by Smith and Code.? The latter authors observed that the ingestion of a fatty meal leads to a decrease in the amplitude and an increase in the frequency of contraction. The discrepancy between other workers and our results may be due to several factors. The Thiry loop utilized in this study, although consisting of half the duodenum, may not provide sufficient surface to initiate the inhibitory effect of fat. The amount and type of fat utilized in the loop may not be of sufficient quantity or in the proper physical-chemical form. The motor stimulants used may have been too potent to be inhibited by the substances in the duodenum. In our feeding studies, the presence of the various nutrients could have overridden any influence of materials placed in the loop. The variable responic among the dogs could have masked the response exerted by the materials in the loop. 
Finally, the variance mat be due to the different methods of assessing gastric contractility. The utilization of acute procedures, surgical alterations, and intraluminal derices could alter the physiologic environment. In our experience, the normal stomach in an interdigestive state is active for only onethird of the time. The inhibition reported by various investigators could conceivably have been a variable of the above time factor, or the alteration of gastric motility induced by various intraluminal devices could be more readily inhibited by substances in the small bowel than is the motility induced by Ach, 5-HTP, or food.

\section{SUMMARY}

This study was initiated to evaluate the effect on contractility of the longitudinal and circular muscles of the canine gastric body and antrum when micellar fat or bile was instilled in a Thiry loop of duodenum. These studies were performed while the animals were stimulated by food, acetylcholine, and 5-hydroxytryptophane (5-HTP). The latter two chemicals were infused for a \$0-min. period. Micellar fat in the duodenum tended to decrease the frequency and amplitude of contractions only in those experiments using 5-HTP or the lower dose of acetylcholine $(50 \mu \mathrm{g} . / \mathrm{kg} . / \mathrm{min}$.) as stimulants. This trend was not seen when bile alone or saline was placed in the duodenal loop. The data were evaluated by a motility index technic and analyzed by a paired comparison method.

\section{P. B. \\ Parke, Davis and Company 2800 Plymouth Rd. \\ REFERENCES Ann Arbor, Mich.}

1. Quicex, J. P., Zerrfinsx, H. J., and IVY, A. C. Analysis of the factors involved in gastric motor inhibition by fats. Amer J Physiol 108:643, 1934.

2. Sмrr, A. W. M., and Covf. C. F. The effect of an ordinary and of an excessively fatty breakfast on human gastric antral motility. Gastroenterology 35:398, 1958.

3. MeNcey, R. Role of biliary and pancreatic secretions in the inhibition of gastric motility by fat in the intestine. Amer J Dig Dis 5:792, 1960.

4. JАСOBY, H. I., B.SS, P., and BEN`ETT, D. R. In vivo extraluminal contractile force transducer for gastrointestinal muscle. I Appl Physiol 18:658, 1963.

5. BAss, P., and WiLEY, J. N. Electrical and extraluminal contractile-force activity of the duodenum of the dog. Amer J Dig Dis 10:183, 1965.

6. ReINke, D. A., Rosevbut, A. 11., and Bexverr, D. R. Patterns of dog gastrointestinal contractile actisity monitoted in vivo with extraluminal force transducers. Amer $J$ Dig Dis 12:113, 1:67.

7. Fingri.t. J. I.. and IIy. I. C. Stulies on the motility of the transplanted gastric pouch. Amer $J$ Physiol $76: 2027,1926$.

8. Frazir, A. C. "Wutne Surface Phenomena in the Study of the Ibsorption of Fat from the Small Intestine." In Surfare Phenomena in Chemistry and Biology, Danielli, J. F., Park. hurst, K. G. A., and Riddiford, E. C., Eds. Pergamon. New York, 1958, pp. 299-307.

9. Horman, A. F. A phwicoshemical approach to the intraluminal phase of fat absorption. Gastroenterology 50:56, 1 \%6it.

10. Kontirex, S., and Grosmas, M. J. Effect of perfusion of intestinal loops with acid, fat, or dextrose on gastric scretion. Ciastroenterology 19:181, 1965. 
11. Swan, K. G., Konrcrek, S. J., Jacobson, E, D., and Gromsina, M. I. Inhibition of gastric secretion and motility by fat in the intestine. Proc Soc Exp Biol Med 12l:840, 1\$66).

12. Anderson, J. J., Bolr, R. J., Lll.mi, B. M., and Bass, P. Differential response to various stimulants in the bokly and antrum of the canine stomach. Amer J Dig Dis 13:147, 1968.

13. JACosY, H. I., and Brodie, D. A. Gastrointestinal actions of metoclopramide. Castro. enterology $51: 676,1967$.

14. Lubwick, J. R., WheE, J. X., and B.sss, P. Electrical and extraluminal contractile-force activity of reversed canine ductenum. Gastroenterology (In press).

15. Vantrappen, C., Hellemans, J., and Vanbenbrolcekr, J. $A$ method for analysis of intestinal motility records. Amer J Dig Dis 10:449, 1 \%6..

16. Connell, A. MI., Texter, E. C., and Vasirappen, C. Classification and interpretation of motility records. Amer J Dig Dis 10:481, 1965.

17. Rosenbaum, A. H., Reivke, D. A., and Beviktr, D. R. In vivo force, frequency, and velocity of dog gastrointestinal contractile activity. Amer J Dig Dis 12:142, 1967.

\section{Postgraduate Course on Gastroenterology}

A postgraduate course titled "Frontiers in Gastroenterology" will be held on May 12-15, 1968, at the Bellevue-Stratford Hotel, Philadelphia, Pa. The course is sponsored by the American College of Physicians and The American Gastroenterology Association. Cochairmen are Henry Tumen and James Roth.

There will be 8 sessions covering the following topics: The Sequelae of the Surgical Treatment of Duodenal Ulcer; Adverse Drug Reactions on the Gastrointestinal Tract; Chronic Pancreatitis; Granulomatous Colitis-Entity or Enigma?; Gastrointestinal Microbiology; Mesenteric Vascular Disease; Chronic Active Hepatitis; and Motor Disorders of the Esophagus.

For further information, please contact The American College of Physicians, 4200 Pine St., Philadelphia, Pa. 19104. 